\title{
Creating A Bigger Z.P.D. For ESL Learners Via Online Forum In Malaysia
}

\author{
Supyan Hussin, Universiti Kebangsaan, Malaysia
}

\begin{abstract}
Formal learning usually takes place in a physical classroom. An extension of learning process may continue to occur in a conventional setting where learners get together physically after class hours. In other words, learning may take place within particular zones. Vygotsky's idea of zone of proximal development (ZPD) suggests that learning may not only take place within a prescribed zone but also outside the prescribed zone. The prescribed zone usually has a set of objectives to be achieved by the learners. However, during the learning process, some learners may learn and/or acquire more knowledge or skills beyond targeted objectives if there is room for students to do so. The non-prescribed zone is determined by the learners' own initiatives and efforts. With the advancement of internet technology, second language learners are now able to extend their learning/acquisition process via online forum. This paper will describe how second language learners viewed online forum activity that was used in two separate classes for two consecutive semesters at a Malaysian university. It will also discuss some pedagogical principles in implementing online forum in courses and a few implications that need to be considered by policy makers, teachers/instructors, and ICT coordinators.
\end{abstract}

\section{INTRODUCTION}

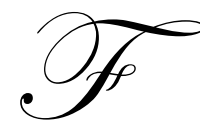

or non-native English language speakers in Malaysia, learning English as a second language is a great challenge. It is quite interesting to observe how English is learned in Malaysia. Before Malaysia's Independence in 1957, the English language was considered as important as the national language, i.e. the Malay language. Most educated Malaysians were bilingual. English remained as a Second language in Malaysia until 1975 when a new language policy was introduced in early 70s that the medium of instruction in all schools should be carried out in the Malay language. As a result, English became a subject course instead of being used across all subjects. Following this turning point, a requirement for students to pass the English examination paper was also dropped off, and yet students could continue their education at high school level even if they failed their English paper. For the next 20 years, English was perceived as a foreign language rather than a second language to the Malay language. Hence, the status of English language in Malaysia has declined since then. Later in response to economic recession in 1997 in Malaysia, the Malaysian government took a few drastic actions to reform the economy in Malaysia. The needs for more graduates and k-workers who could speak English well and who are able to work in multinational companies were listed as important strategies. To meet such needs, the government reversed the English language policy in schools. Beginning 2003, the medium of instruction for Math and Science subjects started to be taught in English. Having, at least, a credit in English in the national school examination would be an advantage for students to be accepted at public universities. Now English becomes a second language in Malaysia again. Indeed, with the advancement of technology in the classrooms, the way students learn English in Malaysia may not be the same as it was before.

No one can master the language overnight. Language learning is a process, and may take place formally and informally. Formal learning usually takes place in a four wall classroom. Learning happens when learners have met the prescribed objectives after being able to perform expected tasks or behaviors at the end of the lessons. In other words, learning may occur within particular zones, which Vysgotsky (1978) calls zone of proximal development (ZPD). He defines the ZPD as the distance between the "actual developmental level as determined by independent problem solving and the level of potential development as determined through problem solving under adult guidance or in collaboration with more capable peers" (p. 86). Vygotsky believes that when a student is at the 
ZPD for a particular task, providing the appropriate support or assistance (scaffolding) will give the learners some motivation to accomplish a given task. Once the learners, with the help of scaffolding, master the task, the scaffolding can then be removed, and the learners will then be able to complete the task on their own (Galloway 2001). At the initial stage, a little coaching and scaffolding from a "more knowledgeable" person can help learners to succeed in the given task that would otherwise be too difficult for the learners. The learners in this scaffolding process, providing non-intrusive intervention, could be adults (parent, teacher, caretaker, language instructor) or peers who have already mastered that particular function (Schultz 2002).

Logically, the size of the ZPD can be enlarged and extended if language learners are given the opportunities to have access to more information and authentic language materials as well to do more practices on what has been taught. In other words, the language learning process is not limited within the classrooms but may continue to occur in a conventional setting where learners get together physically after class hours. Today, with the advancement of information communication and technology (ICT), the ZPD can even be made bigger during learning process. If ICT is integrated well in the course, learners may be able to go beyond the prescribed learning zone. This potential zone may foster not only learning but also acquisition. If we were to borrow Krashen's concepts of language learning and acquisition, then we can relate the potential zone as being the environment within which acquisition would take place. Unlike learning process which is conscious and formal, acquisition process is subconscious and informal (Krashen, 1981). Theoretically, the two processes, learning and acquisition may be separated but in practice they are not. McLauglin (1985) argues that we cannot draw a line between the two; one may overlap with the other. In face-to-face classroom learning, both learning and acquisition may take place at the same time. In an online forum, learners may learn as well as acquire new information and knowledge while participating in the forum. The more active they are in the forum, the higher the tendency for them to learn and acquire new information and knowledge. Consequently, the more they learn and acquire, the bigger their potential zone will become as shown in Fig. 1 below.

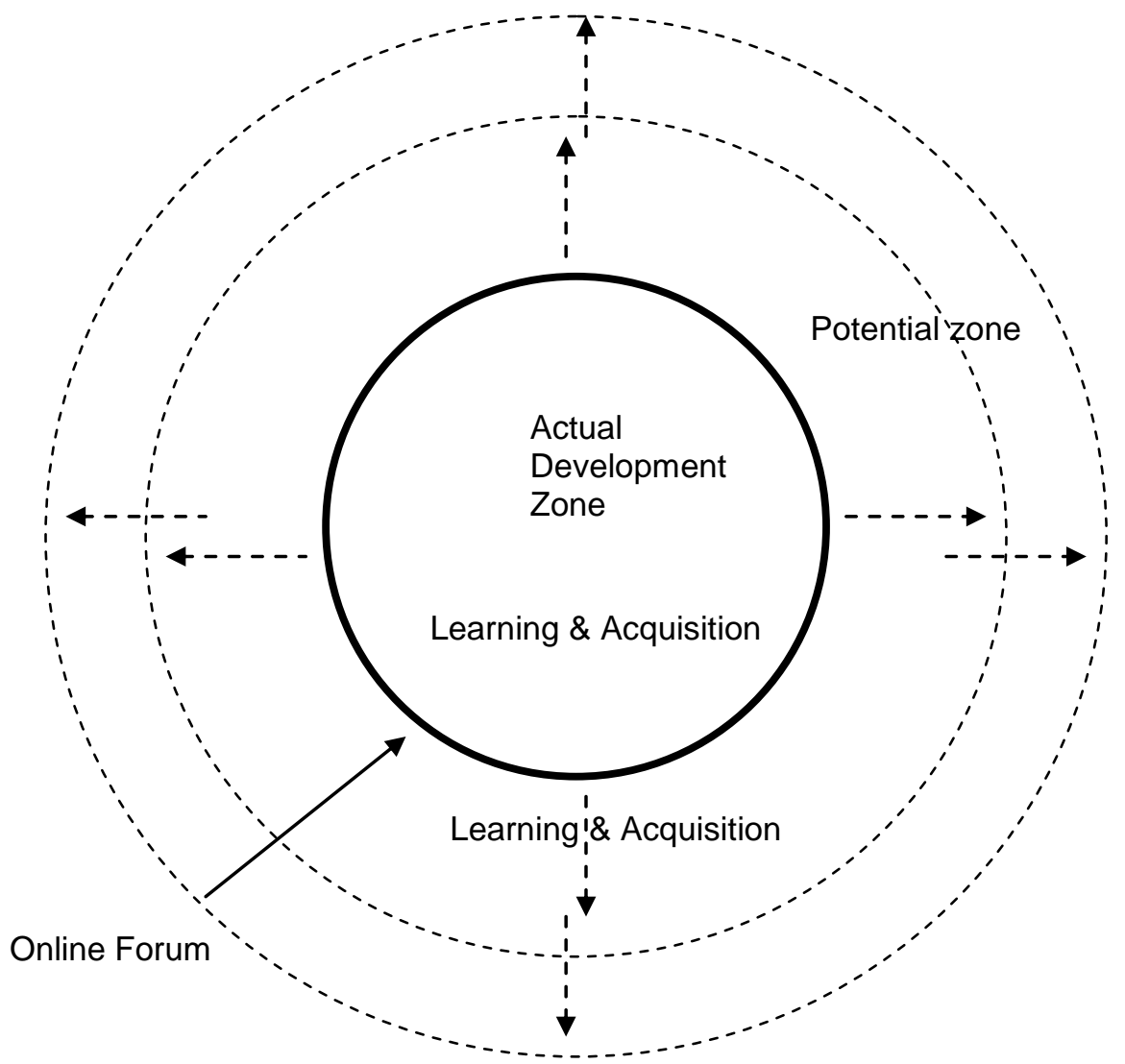

Fig. 1: Learning and acquisition in ZPD using online forum 
In this figure, conceptually, the bold line represents the learning zone prescribed by the teacher in the curriculum whereas the broken lines in the circles represent the potential zone that is determined by the learners. With the support of online forum, learners may extend and enlarge their own ZPD. In this potential zone, language learning and acquisition will be enriched as learners may make use of the existing materials available in the net and share the materials with members in the online forum.

Why online forum (OLF)? Unlike face-to-face discussion in the classroom that is limited by space and time, OLF allows teachers and learners to interact with one another beyond the four walls and specified time. Vygotsky (1978) asserts that learning occurs within a social context, and that interaction between learners and their peers is a necessary part of the learning process. Supyan (2006a) believes that OLF is not merely 'exchanging and posting of messages (ideas, views, questions)' among learners. When OLF inputs are seen related to class lectures, class assignments, and class management, learners would exploit the OLFs optimally. Learners need to understand that their participation in OLF is designed in such a way that they are not only accountable for their own learning but also responsible to contribute to the success of the course objectives. It is during the series of discussions, learners would go through thinking processes as prescribed by Bloom's Taxonomy. While searching for information in the Internet to answer the given questions posted by the instructor in the forum, learners need to read, identify, select, classify, compare and contrast, analyze, and synthesize the information, and later reconceptualize and reconstruct ideas or views that are meaningful to them and share their writings with the forum members. These practices reflect what Doolittle (2001:5) explains how knowledge construction takes places from the constructivists' point of view:

Students interact with knowledge within a sociocultural environment. This external social experience causes the formation of internal mental structures that are influenced by the presence of social, cultural, contextual, and activity-based factors. The student does not acquire an exact representation of this knowledge, but rather, a personal interpretation of the external knowledge. The newly constructed knowledge will be based on the student's prior knowledge and the impact of the social, cultural, and activity-based factors.

For a language class, OLF provides a new environment in which learners can use the language as well as interact with non-native and native speakers of the target language. The learning process in the classroom can now be extended to a virtual environment where language acquisition can also take place. For some learners who are shy to speak up before a group of people, OLF offers an element of privacy in social interaction. Fears of being seen in public and real identity of the users are suppressed in this virtual interaction. It is during the discussion, learners are believed to be able express themselves, share their views, and acquire new information or knowledge. How true is it in Malaysian context? To what extent learners have benefited from the discussion in the OLF? Does OLF help learners to improve their language proficiency? If yes, in what way and how? These are questions that need to be addressed here.

\section{PAST STUDIES}

Studies abroad on advantages of OLFs in education are numerous. Kern (1995) found that OLFs promote increased participation among learners. Beauvois and Eledge (1996) and Swaffar (1998) stated that OLFs provide possibilities for new interpersonal contacts and communicative engagements. Kern (1995), Warschauer (1996) claimed that OLFs produce improved quality language outputs. Warschauer (1996) further argued that OLFs provide a more equitable platform and a less threatening environment for second language discussion. In terms of learners' performance, Yu-Chih and Cifuentes (2001), Thirunnayanan and Perez-Prado (2001/2002), stated that learners who often participated in OLF did better in the course than their friends who practiced face-to-face or offline meetings with teachers.

In Malaysia specifically, OLF is becoming popular especially at colleges and universities. Studies have been carried to observe the practicality of OLF, the effectiveness of OLF, and the benefits or usefulness of the OLFs in language classes at local universities in Malaysia. For example, a study (Malachi 2006) in a literature course at the Universiti Putra Malaysia reported that OLF had enriched learners' knowledge about literature reading of short stories. Learners perceived OLF as a useful tool for communication among themselves while learning literature. As a result of the interaction, learners seemed to understand the literature better Another study (Masputeriah 2006) in 
ESP (English for Specific Purposes) courses at Universiti Teknologi Malaysia (UTM) indicated that OLF was perceived as a platform that (1) offers opportunities for learners to produce, monitor, and improve their language outputs, (2) allows the teacher to provide individualized feedback to learners who need help in some areas of language learning, (3) promotes greater interaction among learners, and (4) provides a less stressful environment especially for those who are poor in their language proficiency.

Next, a study (Norlida 2006) in writing courses offered at Universiti Tenaga Nasional (UNITEN) found that learners' participation in OLFs helped them to learn from one another in terms of feedbacks that they gained to improve the contents of their writing, language structure, and organization of their essays. The use of process writing approach and the integration of OLF in the writing course had helped learners to write with confident and produce better writing outputs.

Two studies were carried out at Open University Malaysia (OUM) in relation to OLF. Kuldip Kaur and Harvinder Kaur (2006) found the exchange of ideas about selected topics in the OLF led to open discussion and constructive criticism among adult learners. The thread discussion in the forum had successfully promoted a knowledge construction process in the course. In another study at OUM, Supyan (2006b) found that learners were in favor of reading the messages rather than contributing inputs in the forum; majority expected their instructor to be an active player in the forum (i.e., moderate the forum, respond to learners' inquiries within 48 hours); and many expressed their time constraint as a major factor that limits their participation in OLF.

In a series of studies carried out for two consecutive semesters (2005-2006) in language courses at Universiti Kebangsaan Malaysia, Supyan (2006a) concluded that (1) learners could benefit a lot from both classOLF and other-OLF in terms of in-depth understanding of the lecture contents and class assignments; (2) OLF is more meaningful to members when the OLF has focused group, a focused theme, and a form of incentive (3) since writing in public may reflect the identity and value of a social being in the forum, students with low self-esteem and low self-concept might be afraid to participate in OLF openly; and (4) OLF would be more dynamic if the teacher posted questions in the forum and moderated the discussion.

Last but not least, Faizah (2006) found that OLF could foster critical thinking in second language environment in her language course at Universiti Teknologi MARA (UiTM). The OLF offers a reflective discussion platform for second language learners to post, respond, critic, and justify their opinions without any reservation or embarrassment. She claimed that such activities could not be carried out in face-to-face meetings in conventional classroom. However, the increased participation was not significantly correlated with critical thinking.

Based on the above discussion, we can conclude that OLFs offer opportunities to individual learners to extend their learning zone from the 'actual development zone' to 'potential additional zone' in their learning process. Further analysis of the above studies unfolds a few pedagogical procedures that are commonly shared by the researchers.

- $\quad$ OLF is one of the activities in language classes, either independent or inter-related with other activities.

- $\quad$ Participation in OLF is graded, although the grade may vary from one setting to another.

- Learners are expected to make use of the information from the forum in other class assignments.

- $\quad$ The teacher plays a major role in guiding, monitoring, and moderating the forum.

- The amount of time spent in the forum contributes to learners' performance in the course.

\section{A RECENT STUDY}

A study was carried out at UKM, involving 30 learners (i.e., 12 males and 18 females), from B.A. English Language program between January and March 2007. The same 30 learners had also participated in a different forum from July to November 2006. This study is a follow up of the earlier research. One of the tasks assigned to the learners in the course was participation in an OLF, using yahoo group facility. Each student was required to exchange opinions, share ideas, and discuss issues posted by the lecturers. Topics posted were related to lectures and class assignments. Some questions posted in the forum derived from the face-to-face class discussions. Other 
messages such as social and daily routine activities that are not related to the course were disallowed in the forum. Their participation was graded, and a maximum score for the participation was 15 percent of the total score. Each posted message carried 1 mark, and each student was expected to post a minimum of 15 messages throughout the 14-week course. The content of the message should be relevant, adequate, and reasonable, and should not merely a short one or two sentence. Learners were not penalized for their language errors but they were reminded to proofread their writing before sending it into the forum. An emphasis was given on substantial content and active participation. Although 'cut-and-paste' and 'copy-and-paste' of information from websites were allowed, learners needed to acknowledge the sources. Some of the contents of the discussion were used in the final examination. At the end of the semester, learners were given an open-ended questionnaire for feedback on OLF activity in the course: (1) To what extent is OLF beneficial and meaningful to you in learning? (2) Do you think the OLF had helped you to improve your language proficiency? If yes, how?

\section{RESULTS}

The discussion of the results is based on the following question. (1)To what extent is OLF beneficial and meaningful to you in learning?

These are examples of learners' responses:

Ai Ching: Students can improve their language proficiency through participating in online forums; how to access the internet; students learn something that is not in the textbooks.

Azizul: Content of the discussion is always useful to students; learners will equip themselves with the skills, knowledge and personal qualities needed for life and work.

Deepa: Free to express what is on their mind; interact with others and learn. Discussion though online forum very much help for me; student and teachers can learn from each other; to share more ideas and express themselves. Expand their use of vocabulary, knowledge in particular language such as English.

Faeiz: Make an online research about the topic; teacher can give feedbacks whether students are on the right track people/students to discuss among each other. Online forum can be beneficial as the inquiries about something will get immediate feedbacks from the active netters. Can also create a friendly learning environment? Exchange ideas and talk about anything without any barrier. People from all over the world can interact nonverbally and exchange information

Farhana:Forum allows the students to write more to sharpen their writing skills.

Farhana: Good in terms of learning because the discussion is based on specific topics.

Hadi: Everybody can respond. It is not complicated; it can be very interesting process in learning which requires students to think creatively; extra and relevant topics

Halimath beevi: Share opinion among peers; lecturer give feedback on their input

Hanafee: The contents gives more info since the internet is inter-related; generates critical and creative thinking. Getting comments from people allows for self-improvement, motivation to write and others. The more you write, the more proficient you get with the language.

Hasanul: Topics related to what have been taught; do research and learn as well

Husna: Student feel more encouraged to write and express their idea. Students can find extra information.

Loke wan: Relevant topics to the related course. Helps search for other sites that have even more information.

M. Azizul: Share the information discussed; improve their knowledge; extra but relevant topics are discussed in the forum

Marylyn: The more feedback students give, this will improve their writing ability; students can get more content online and discuss about a specific topic in the forum; learning will be more interesting

Munirah: Can ask things that they didn't understand; alternative source for students to get information. Helps students to expose themselves through the technology enhancement. One way that teachers help their students on using multimedia application in their learning process.

Nadia: Can help students understand more interact with lecturers

Nazaturazah: Experience new things that can expand their views also; helps students to practice their writing skills. Helps build students' confidence 
Norherizan: Encourage students in being self confident; students might learn new things and they'll have new information

Norsiah: That makes someone more informative when joined the forum.

Nur rashidah: Helps them to be more confident when communicating in public. Able to provide advice and feedback on the spot; Able to motivated students to get involved in web forum.

Nurul huda: By the discussions, students would be able to give their opinion, knowledge that are related to the topic and share it with others. Offers input to both conscious and unconscious learning process to practice and receive feedback on performance. One is encouraged to write more online. Benefit from practice of writing.

Paakkialetchumi: Sharing of ideas and knowledge with others; students will be ore active in searching materials or extra notes.

Parimala: Look for info on copyleft and ten share it among friends; learning more then they (forum members) are supposed to. Rich in knowledge. Promotes research activities among students

Rosnanil: Students can see a lot of idea: more understanding and knowledge. Search materials

Sharul: Help students to improve and enhance their language competency in the way of voicing out the ideas, suggestions and so on. Students are able to give comments on other friends work.

Supria: Teachers can view students' works anytime and anywhere. It is convenient and flexible

Vikneswari: Forum gives immediate feedback. No barrier of word; extra discussions which is made too, where it makes online forums fun and more rich in content and helps the students in their communication too. immediate feedback; interaction \& acquisition in writing \& reading

William: Serious in participating, they can improve their language ability

Wilter: Alternative way to learn and study; sites give them idea of the topic; construct ideas

Wirna: Huge effort to search for the information; scramble with different topics

What can we say about the above responses in relation to the question asked?

Learners found that the OLF conducted in the course is beneficial and meaningful when:

- $\quad$ The discussion is moderated by the lecturer who is teaching the course

- The discussion is not a repeat of what has been lectured in the class rather an enforcement and enrichment of the topics; and related topics are introduced by asking learners to look for information on the particular topics and share their findings with the members in the forum

- $\quad$ The topics are focused and related to the course content,

- The objective of the discussion was not for the sake of the discussion but to generate new understanding and to enlarge as well as extend their learning zone

- $\quad$ The essence and content of the discussion would be used in the quizzes and final examination.

- $\quad$ The evaluation of the forum is not so much on the language but on the substantial content of the discussion; in other words, learners are not penalized for their language errors or mistakes. The emphasis is more on the content and fluency rather than form and accuracy of the language.

Having said that, let's move to the second question. (2) Do you think the OLF had helped you to improve your language proficiency? If yes, how?

These are examples of learners' responses in relation to this question:

Ai chin: They (students) will also improve their vocabularies

Azizul: Students must read a lot of materials in the website or book to improve the language proficiency

Farhana : Improve their language proficiency especially in their writing skills.

Haasanul: Read intensely and understand it first

Hadi: Be so beneficial for those who read

Halimath: They can improve their language writing by posting their essay and asking for comments on their writing. Can improve their reading skills while finding materials. 
Hanafee: Allows us to interact with native language users which allows us then to realize mistakes and make corrections; helps proficiency through research; through reading; through writing; improve reading skills because they need to read more before answering the question being given; improve vocabulary and grammar

M.Azizul: Write and gain experience and this gradually will make them a better writer.

Marylyn: students can write creatively in the forum; can help students to improve their language proficiency. Students can improve writing skills

Munirah: can also help students to develop their writing skills; feel free while writing, points are more important; read and select some of the main points

Nadia: Students must read article first before pasting in forum, therefore gain knowledge

Norsiah: Students can improve their writing skills through online forum because they can write anything they want without penalty by others; improve our vocabulary and grammar

NurRashida: Able to develop their grammatical competence. Able to write as much as we want; aware of the grammatical items, they learn and make errors during writing.

Nurul: The encouragement to students to practice their language by writing. be an easy way for teachers to do distant learning; writing more and more, they will become more competent.

Paakkialetchumi: Express ideas or opinion without stress on language errors. Build language skills by reading and understand what materials are all about.

Rosnani: Must think and read for the related topic; improve their reading skill; Students get more vocabulary from others while being online; Students participate and write according to their own level.

Supria: Students are able to write their comments, suggestions \& opinions. They get better and improve their writing skills everyday.

Vikneswari: Helps the student to revise for their exam; when they read their friends comments, they will somehow learn more words

Wan Tim: More freedom in expressing how they feel about certain topics. Practice their writing skills; writing very long postings; students could benefit by interpreting other students' ideas.

William che: Topic related to lecture and can be treated as extra information.

Wilter: Activates our inactive word

Wirna: Learn from mistakes of members; opinion freely

A few conclusive statements can be derived from the above responses. Learners had a mixed view on whether OLF would help them in language proficiency:

- $\quad$ About a half of the population believed that OLF did not help them to improve their language since

- the lecturer ignored their language errors and mistakes yet focused on the content of the discussion

- some learners simply 'cut and pasted' or 'copied and pasted' contents they found from other sites although they had to provide URL sources

- $\quad$ Another half the population believed otherwise:

- they learned from the language errors and mistakes committed by their friends.

- they could practice their reading skills and apply the thinking skills based on Bloom's taxonomy (identifying, classification, compare and contrast, analyzing, synthesizing) and later reconceptualizing as well as reconstructing meaningful ideas when they presented their arguments or views in the forum.

- they could practice their writing ability when presenting their views regardless of whether they might make language errors or mistakes.

\section{DISCUSSION OF FINDINGS AND IMPLICATIONS}

These recent findings on the use of OLFs in language courses are compatible with that of past findings. First, we notice that the OLF is more than simply exchanging ideas, views, and questions among learners. Learners find OLF meaningful and beneficial when the discussions in the forum are related to class lectures, course assignments, and course assessment. Hence, learners would pay more attention to the forum. The thinking processes that they had gone through have made them become active learners. 
Second, OLF in should not be conducted as a minor activity in language classes when the benefits of this platform are multiples. In other words, the OLF should not be conducted in isolation but be related to other activities that are assessed and graded reasonably. When OLF in are made relevant to other activities in the course, learners may appreciate the OLF, become more active in the forum and thus, contribute more inputs to the forum. Learners' participation in OLF is like a small piece of puzzles that will make up a larger picture of knowledge presented by the teacher.

Third, the time spent for accessing the forum, reading the messages, responding to messages, and posting messages (ideas, views, questions) worth the learners' efforts. Small percentage of assessment score is insufficient to motivate learners, especially lurkers, to participate actively in the forum. The higher assessment score can be a good incentive that will push or encourage learners to become active players in the forums. Nevertheless, the higher score is not the only form of extrinsic motivation. Recognitions made by the teacher in the forums through praises, agreements, and confirmations could also comfort learners' feelings and attitudes towards OLFs.

Fourth, poor language used by members in OLF should be penalized in the assessment process. Grammar mistakes, fragments, abbreviated words or short cuts, and incomplete sentences committed by learners should not be graded. What more important in the OLFs is learners' active participation and substantial content contribution. In this case, accuracy of the language perhaps should be secondary, provided that the messages are comprehensible to members. This is in line with what Krashen proposed in his Monitor theory (Krashen, 1981). However, in a more formal setting, accurate language use is necessary so that learners, especially second language learners, may acquire correct language inputs.

Last but not least, the role of teachers should be made clear to learners. In OLF, on one hand, teachers act as a moderator and a facilitator. Teachers are not supposed to teach in the forums as they do in the classrooms. Teachers moderate the discussion in the forums by triggering some questions or inquiries. They need to monitor and harmonize the discussion so that the objectives of the course are met. On the other hand, the teacher should not rigidly control the discussion.

\section{CONCLUSION}

OLF is new in education setting in Malaysia. It should be used as a leisure activity which may not be graded seriously. If an OLF is practiced properly by taking into consideration language pedagogical principles, it could promote a bigger zone of proximal development during the learning process. Although the size of the zone may vary from one learner to another, depending on individual's abilities, learners might learn and/or acquire new knowledge and skills continuously; subsequently, they might enjoy becoming autonomous learners as they could explore the possibility of enlarging and extending their learning and development zone. Adopting OLF in language classes is a very practical move given the fact that it is becoming a norm in education world wide. Keeping infrastructure, hardware, and software as constant variables, teachers need to understand the potential benefits of OLF. Subsequently, language teachers need to acquire certain pedagogical procedures that are appropriate for their own courses. Recognizing the importance of the quality of the discussion and its contribution in the knowledge reconstruction in the classrooms, teachers should allow present generation of learners to engage in a larger context of communication via OLF so that these learners will become more responsible in their own learning process. Such practice is hoped to inculcate new values in life long learning process among language learners upon graduation. One of the possibilities for future study is to trace whether these learners, who have been participating in OLFs, would continue to be part of OLF or e-communities that are relevant to them after they graduate from the university. For teachers who are interested in action research, the amount of discussion in their OLFs can be a group of valuable data for some analysis provided that those data are not deleted from the server at the end of the course. Policy makers should allocate funds for upgrading the infrastructure as well as human resource development and training program so that present institutions can offer a better quality of education for the future generations. 


\section{REFERENCES}

1. Beauvois, M.H. \& Eledge. J. 1996. Personality types and megabytes: Student attitudes toward computermediated communication (CMC) in the language classroom. CALICO Journal, 13(2 - 3): 27 - 45.

2. Doolittle, P. 2001. Integrating constructivism and cognitivism. Educational Psychology. (online) http://www.tandl.vt.edu/doolittle/research/icc.html. (18 Feb 2007)

3. Faizah Mohammad. 2006. Face-to-face and online discussion on language classrooms. Proceedings of 6th Annual Southeast Asian Association for Institutional Research SEEAIR 2006 Conference: Transforming Higher Education for the Knowledge Society. Kuala Lumpur: SEEAIR-OUM, 478 - 487.

4. Galloway, C. 2001. Vygotsky's constructionism. (online) http://www.it.studio.coe.uga.edu/ebook/ 14 Feb 2007).

5. Kern, R.G. 1995. Restructuring classroom interaction with networked computers: Effects on quality and characteristics of language production. The Modern Language Journal. 79(4): 457 - 476.

6. Krashen, S. 1981. Second Language Acquisition and Second Language Learning. Oxford: Pergamon.

7. Kuldip Kaur and Harvinder Kaur. 2006. Bridging the distance in ESL teacher education: Strategies for effective facilitation in collaborative online learning. In Muhammad Kamarul Kabilan Abdullah, Norizan Abdul Razak \& Mohd Amin Embi (Eds). Online teaching and learning in ELT. Penang: Universiti Sains Malaysia, $251-267$.

8. Malachi, E. 2006. Computer mediated communication in literature learning. In Muhammad Kamarul Kabilan Abdullah, Norizan Abdul Razak \& Mohd Amin Embi (Eds). Online teaching and learning in ELT. Penang: Universiti Sains Malaysia,177-194.

9. McLaughlin, B. 1985. Second-language acquisition in childhood (Volume 1): Preschool children, 2nd ed., Hillsdale, NJ: Lawrence Erlbaum Associates, Inc. Publishers,.

10. Masputeriah Hamzah. 2006. Use of computer mediated communication to facilitate second language acquisition. In Muhammad Kamarul Kabilan Abdullah, Norizan Abdul Razak \& Mohd Amin Embi (Eds). Online teaching and learning in ELT. Penang: Universiti Sains Malaysia, 159 - 176.

11. Nielsen, Jakob 2006. Participation Inequality: Encouraging More Users to Contribute. Online http://www.useit.com/alertbox/participation_inequality.html. (Retrieved on 11 Nov 2006)

12. Norlida Alias. 2006. CALL - A Study of Network-based Learning in a Writing Course: Perceptions of Usefulness. Doctoral Dissertation. Universiti Kebangsaan Malaysia.

13. Nuraihan Mat Daud \& Ainol Madziah Zubairi. 2006. Online and offline writing course. In Muhammad Kamarul Kabilan Abdullah, Norizan Abdul Razak \& Mohd Amin Embi (Eds). Online teaching and learning in ELT. Penang: Universiti Sains Malaysia, 7 - 20.

14. Schutz, R. 2002. Stephen Krashen's theory on second language acquisition. (online) http://www.sk.com.br/sk_krashen.html. (20 Jan 2007)

15. Supyan Hussin. 2006a. Revisiting online forum in language teaching. Plenary paper presented at ASIACALL. 26 - 28 Nov 2006. UPM.

16. Supyan Hussin. 2006b. Online forum in ELT Training Program: Constraints or Problems? Proceedings of 6th Annual Southeast Asian Association for Institutional Research SEEAIR 2006 Conference: Transforming Higher Education for the Knowledge Society. Kuala Lumpur: SEEAIR-OUM, 438 - 446.

17. Swaffar, J. 1998. Networking language learning: Introduction. In J. Swaffar, S. Romano, P. Markley and K. Arens (Eds). Language learning online: Theory and practice in the ESL and L2 computer classroom. Austin, TX: Labyrinth Pubications, 1-15.

18. Tan Choon Keong. 2006. The implementation of an online discussion board for coloborative learning. In Muhammad Kamarul Kabilan Abdullah, Norizan Abdul Razak \& Mohd Amin Embi (Eds). Online teaching and learning in ELT. Penang: Universiti Sains Malaysia, 111 - 131.

19. Thirunnayanan , M.O. \& Perez-Prado, Aixa. 2001/2002. Comparing web-based and classroom-based learning. A qualitative study. Journal of Research and Computing in Education. 34(2): 131 - 137.

20. Vygotsky, L.S. 1978. Mind and Society. Cambridge. MA: Harvard University Press.

21. Yu-Chih Doris Shih \& L. Cifuentes. 2001. One tale of why and how to teach online internationally. TechTrends, 45(6): $8-17$.

22. Warschauer, M. 1996. Comparing face to face and electronic communication in the Second Language. CALICO Journal, 13(2): 7-26. 


\section{NOTES}

